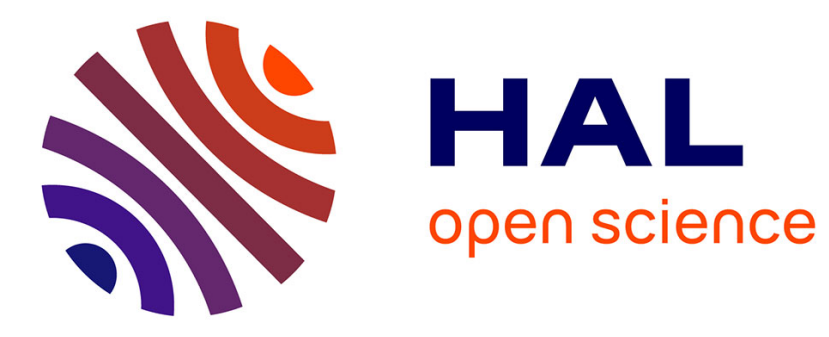

\title{
Lexical Contextualism: The Abélard Syndrome
}

Alain Polguère

\section{To cite this version:}

Alain Polguère. Lexical Contextualism: The Abélard Syndrome. Núria Gala, Reinhard Rapp, Gemma Bel-Enguix. Language Production, Cognition, and the Lexicon, 48, Springer, pp.53-73, 2015, Text, Speech and Language Technology, 978-3-319-08042-0. hal-01083279

\section{HAL Id: hal-01083279 https://hal.science/hal-01083279}

Submitted on 17 Nov 2014

HAL is a multi-disciplinary open access archive for the deposit and dissemination of scientific research documents, whether they are published or not. The documents may come from teaching and research institutions in France or abroad, or from public or private research centers.
L'archive ouverte pluridisciplinaire HAL, est destinée au dépôt et à la diffusion de documents scientifiques de niveau recherche, publiés ou non, émanant des établissements d'enseignement et de recherche français ou étrangers, des laboratoires publics ou privés. 


\title{
Lexical Contextualism: The Abélard Syndrome
}

Alain Polguère

\begin{abstract}
The term contextualism is used in linguistics to refer to approaches that are based on the following credo: linguistic entities cannot be considered outside contexts of use as it is only in context that they do make sense. Contextualism has always existed (at least, since antiquity) and it does not correspond to a uniform approach to language studies. It is however striking that much resonance is given in lexical studies to what could be called lexical contextualism, a radical conception by which words do not have meaning of their own, and by which only contexts "give meanings" to words. This position has many non-trivial implications on lexicographic methodologies, language teaching strategies, and even on the very acceptance of core notions such as polysemy. The goal of this paper is twofold. First, it characterizes lexical contextualism: the axioms it is based on and its implications on lexical studies. Second, it tries to provide explanations for why lexical contextualism can appeal to many in their attempt to account for how words convey meanings.
\end{abstract}

\section{Introduction}

Before being a matter of proof and discovery, science is a matter of belief. Without beliefs, without knowledge that one does not reconsider in the course of reasoning on an object of study, there is no scientific activity. In linguistics, as in any descriptive science, beliefs play a crucial role as no progress can be made if some facts are not taken for granted, if there are no "truths" and if everything has to be perpetually reconsidered and put to a test. The author of the present text is not ashamed to assert that he believes in the primarily descriptive nature of linguistics as a science, in the notion of part of speech, in syntactic dependencies and, unlike some [13], in word senses. The moment one doubts axiomatic facts, the research activity is stopped, the

Alain Polguère

Universitè de Lorraine \& ATILF CNRS, 44 avenue de la Libération, BP 30687, 54063 Nancy

Cedex, FRANCE, e-mail: alain.polguereduniv-lorraine.fr 
fundamental descriptive component of linguistic study is paralyzed and one can do nothing but turn philosophical. There is only one thing that should make scientists reconsider their beliefs: it is if they cannot achieve what they try to achieve with the notional toolkit they are using. Under such circumstances, they have to pause and reflect, and are faced with two options. They can try to diagnose what goes wrong with their approach, see if something can be fixed, see if a better alternative already exists or if a theoretical revolution is required. The alternative approach, more radical and, strangely enough, quite popular is pure and simple denial of the objet of study: if I cannot explain $X$, it means that $X$ does not exist.

This paper tries to be a remedy against this easy way out in lexical studies and, more specifically, against the denial of word senses. Our present target is the doctrine of lexical contextualism, that is so widespread in language studies whether in its explicit or rampant form.

The term contextualism is used in the philosophy of language to refer to approaches that are based on the following credo: the content of linguistic utterances results from contextual (pragmatic) parameters and it is only in context that utterances do make sense $[35,32,36,5]$. Contextualism in the philosophy of language has been extensively discussed-see [23] for a recent criticism of the approachand we are in no position to add a single piece of relevant comment to what has already been said on this topic. Rather, our focus is on a peculiar manifestation of the radical contextualist doctrine in the field of lexical studies (i.e. lexicology, lexicography, vocabulary teaching, etc.): what can be termed lexical contextualism, a conception by which words do not possess meaning of their own, and by which only contexts give meanings to words. Lexical contextualism has always existed (at least, since antiquity) and it does not pertain to a specific approach to language studies. It is however striking that it appeals to many and that it has non-trivial implications on lexicographic methodologies, language teaching strategies, and even on the very acceptance of core notions such as polysemy.

This paper is only a modest essay on lexical contextualism and it does not pretend to "reveal" or build new pieces of knowledge. We will be satistisfed if the fact of expressing our opinion on lexical contextualism and synthesizing observations we have been able to make while studying lexical knowledge can help put linguistic context in its right place in lexical studies. The principle we want to argue for is probably an uninteresting piece of self evidence for those already convinced and an absurd backward conception for the others, but truths often look this way. This principle can be phrased as follows, in three logically related statements:

1. Linguistic context of linguistic units in utterances is determined primarily by lexical rules and grammatical rules that make up the bulk of the Speaker's linguistic knowledge.

2. The meaning and individual combinatorial properties of a lexical unit $\mathrm{L}$ are, in that respect, the fundamental inherent rules associated to $\mathrm{L}$ that condition the various contexts in which the speaker will use $\mathrm{L}$ in speech.

3. Under no circumstances should lexical meaning be considered as determined by context as this would boil down to confusing meaning (Speaker's knowledge) 
with the process of meaning recognition/identification (Addressee's mental process).

The aim of our essay is two-fold. First, it presents both theoretical and practical arguments against lexical contextualism. Second, it tries to provide explanations for why lexical contextualism can appeal to many in their attempt to account for how words convey meanings.

Well, to be honest, this paper has another purpose: it is meant to be a token of friendship to our colleague and old friend Michael Zock. Old is used here as a collocate of friend, synonym of long-time, ${ }^{1}$ and it should definitely not be understood in its literal meaning. Talking about meaning ... let's get down to business.

\section{Contextualism in lexical studies}

By lexical studies, we mean all disciplines for which the study, understanding and treatment of words play a central role. It includes lexicology and lexicography, but also terminology, vocabulary teaching, etc. This section tries, first, to clarify the nature and impact of contextualism in lexical studies (2.1) and, second, to put forward arguments against a radical contextualist perspective on the study of words, that we will refer to as lexical contextualism (2.2). The inadequacy of lexical contextualism can only be pointed at, and not demonstrated. However, laying down arguments against lexical contextualism is a non-trivial exercise as the approach negates the existence of inherent lexical meaning, whereas the focus should be on their study and description. In so doing, lexical contextualism undermines the very foundations of linguistics. To quote Anna Wierzbicka on this matter [37, p. 146]:

My basic premise is that language is a tool for conveying meaning. Though a truism, this proposition is what imparts direction, purpose, and a sense of identity to linguistics as a science.

\subsection{To have or not to have a meaning}

Being a philosophical ignoramus, we would not dare comment on what exactly contextualism is, in its broad sense. We have to humbly admit that we perceive definitions such as the one below—proposed by Jason Stanley [36, p. 119]—as being totally opaque:

Contextualism in epistemology is the doctrine that the proposition expressed by a knowledge attribution relative to a context is determined in part by the standards of justification salient in that context.

\footnotetext{
${ }^{1}$ A Magn ${ }^{\text {temp }}$ of friend, in terms of Meaning-Text lexical functions [17].
} 
It is however clearer to us, though not absolutely clear, what contextualism is in linguistics. To rephrase in very simple terms the definition given earlier in section 1, linguistic contextualism is the credo according to which what is expressed by a linguistic utterance is radically determined by the context in which this utterance occurs. As mentioned in the introduction, there are many variants of linguistic contextualism, and this variability can be explained by at least three facts.

Firstly, context (in which an utterance occurs) is a vague term. It can be the linguistic context, i.e. the co-text, it can be the pragmatic context, or it can be both. Unfortunately, authors do not always make absolutely clear what type of context they are considering. In this paper, only co-text will be considered as relevant. And by co-text, we mean exclusively the linguistic material itself. Non-linguistic knowledge that can be associated with the co-text of an utterance is but pragmatic context.

Secondly, one should make a clear distinction between the notion of informational content and that of linguistic meaning. While the content of an utterance is the information it carries in speech, its linguistic meaning is the information it carries as an assemblage of linguistic signs. We feel almost ashamed to write such a statement, that seems a piece of self-evidence a century after Ferdinand de Saussure's conceptualization of the distinction between langue and parole [34]. But what is an evidence for linguists, lexicographers and grammarians involved in actual descriptive work is often overlooked by those who are in the business of discussing, rather than describing, languages.

Finally, linguistic contextualism is a gradable notion, ranging from "mild" [32] to "radical" [35] variants. From a radical perspective, nothing can be said about the meaning of lexical units, phrases, etc., as it is only once they appear in given linguistic and pragmatic contexts that they do carry a given informational content.

There is no point discussing mild linguistic contextualism. It goes without saying that context plays a definite role in determining the semiotic value of utterances, the same way it participates in any Peircian semiosis [31]. The following quotation from Martin Montminy [23, p. 320] seems to summarize perfectly well this rather non-controversial approach to contextualism:

What is asserted is closely related to the sentence uttered: figuring out what is asserted is a matter of "fleshing out" the meaning of the sentence so as to obtain the proposition that the speaker primarily means by her utterance. We could characterize what is asserted as a slightly enriched version of what is explicitly expressed by the utterance. Thus, what is asserted could have been made explicit simply by inserting some lexical material at the relevant place in the sentence uttered.

Additionally, we should not argue against the fact that words do not "mean" by themselves. They "have a meaning," i.e. an inherent property that conditions their denotational effect in semiosis but, considered by itself, a word is just like an unlit lightbulb. This is why authors often call on the term $[a]$ potential when characterizing the nature of word meanings. See, from a contextualist perspective, François Recanati's semantic potential [32, p. 152]:

There is something which words do contribute, and which is sufficient to account for the difference it makes when we substitute a word for another one. That thing is not a 'meaning' in the traditional sense: it is what I called the 'semantic potential' of words. 'Red' and 
'rectangle' have very different semantic potentials. The semantic potential of a word is the collection of past uses on the basis of which similarities can be established between the source situations (that is, the situations such uses concerned) and the target situation (the situation of current concern). So there is, indeed, interaction between the 'context' and what words themselves contribute. Context does not do everything, even on the most extreme form of Contextualism.

In the same vein, but in a more descriptive perspective, Kerstin Norén and Per Linell [24] adopt the notion of meaning potential.

Anna Wierzbicka, from a lexicologist perspective, acknowledges the notion of meaning as a non-autonomous property seen as descriptive potential, while insisting on the fact that word meanings are constant values that can be identified and described if the proper tools are used [37, p. 147]:

(...) a word is not a container with hidden contents which can be extracted or a black hole whose contents can be suddenly illuminated. Different words "mean" different things in the sense that they can make different contributions to communication. These contributions can be compared if we have some standard of measure for "measuring" (describing) different words' communicative potential (that is, their "meaning").

In what follows, word meanings as non-autonomous properties and contexts as necessary parameters in linguistic semiosis are taken for granted. Only radical contextualism is subject to discussion as it boils down to negating the existence of linguistic meaning. As specified above, within radical contextualism, it is specifically lexical contextualism that will be our focus of attention. Lexical contextualism can be more of less equated with what François Recanati terms meaning eliminativism and claims "is implicit in the writings of some of the early contextualists (Austin, Wittgenstein, and others)" [32, p. 141].

\subsection{Lexical contextualism "at work"}

The most direct consequence of lexical contextualism is the negation of the lexicosemantic module of natural languages. As no inherent information can be associated to words, lexical meanings (among others) cannot be considered as part of the language. And the corollary of this is that any enterprise that aims at identifying and describing lexical meanings is by nature futile.

It is interesting to notice that radical contextualists are quicker at working on the omnipotence of context in regards to lexical meanings than they are in regards to, say, grammar rules. But if lexical meaning can be negated, why not also consider that grammar rules do not exist per se and that structural organization of utterances exists only in context? Afterall, no one has ever "seen" a syntactic or morphological structure. If meanings do not exist, we can as well consider that grammar also, and the whole of language do not exist. If languages do not exist, what are we doing here?

Languages-lexical units, their individual properties, grammar rules, etc.-are learnt. Learning means acquiring information. In the specific case of languages, we 
acquire rules from our interaction with the social environment. Language is not reflex. Language is knowledge. And the primary role of linguistics is to account for that knowledge. Therefore, radical contextualism, and particularly lexical contextualism, has simply no place in linguistics. It can be discussed from a philosophical point of view, like any productive or counter-productive idea. But it can only act as an intellectual poison once poured in the field of linguistics because, as has just been said, it simply negates the object of study of this science.

Science is not only meant to satisfy our curiosity. Curiosity is an important factor in the dynamics of science, which allows some to state that science is self-justified as a means to satisfy an inherent "knowledge hunger" in human beings. However, giving science a free-ride is a dangerous and self-destructive attitude. Ultimately, the outcome of scientific activity is not the publishing of texts, the organization of conferences and the thickening of CVs, it is the successful exploitation of scientific results for external purposes, i.e. activities that are either non-scientific or belong to other scientific domains. In the specific case of linguistics, these activities can be language teaching, translation, computer processing of texts, diagnosis and treatment of language-related pathologies, etc.

And what do we need to obtain from the study of words? The following are obvious answers:

- models of the lexicons (dictionaries, lexical databases) that can be used by language teachers and learners, translators, etc., as references on word-related language rules (meanings or "descriptive potentials" being central);

- formal models that can be used by computer programs to perform linguistic tasks;

- greater insight on how lexical knowledge evolves;

- greater insight on the global structuring of lexical information from linguistic, neurological, psychological, etc., perspectives.

Now: which approach, considering word meanings (i) identifiable properties or (ii) evanescent and fully context-bound phenomena, will get us closer to meeting the above-mentioned societal needs? The answer seems obvious. Additionally, we wonder if the advocates of lexical contextualism realize that, because of their belief that words do not have meaning, they are not entitled to ask or answer such natural questions as "What does irony < grin, poneytail, direct object ... > mean?" One can wonder what kind of parents, teachers or friends they would be if they were to truly stick to their principles in daily life. For this reason, we tend to not believe those who say that they do not believe in word senses [13].

All this being said, one cannot ignore the influence of lexical contextualism in linguistics, and because we are daily faced with it, it is worth trying to answer a very simple question, the only question that is worth asking, in our opinion: why does sense denial exist? 


\section{Why does sense denial exist?}

We see at least two interrelated facts that explain the overwhelming presence of lexical contextualism in lexical studies: a quasi-metaphysical or philosophical attitude towards words - examined in section 3.1 below — and a methodological linguistic tradition-section 3.2. As will be shown in section 3.3, both are related.

\subsection{Prata (scolaresque) rident}

In an article entitled Prata rident [33], Irène Rosier-Catach analyses Latin texts written by three medieval scholars-Pierre Abélard, Thierry de Chartres and Guillaume de Conches - and elaborates on their conceptualization of metaphorical "semantic transfer" (translatio or transumptio, in Latin).

The Latin expression that serves as title for [33] can be translated as follows, though we will have to discuss this translation later in section 3.1.2: ${ }^{2}$

$$
\begin{aligned}
& \text { Lat. Prata rident } \\
& \text { meadows } \\
& \text { 'The laugh } \\
& \text { meadows bloom' }
\end{aligned}
$$

First, we will explain why the above example is such an emblematic illustration of metaphorical semantic transfer (3.1.1); a detailed structural linguistic analysis of (1) and of other closely related expressions will follow (3.1.2). Finally, we will focus on Abélard's perspective on this type of metaphor — as accounted for in [33] —in order to extrapolate on some possible "philosophical" roots of contemporary lexical contextualism (3.1.3).

\subsubsection{Prata rident: an emblematic example}

The expression prata rident has been much cited by theologians and rhetoricians. Its recurrent mention in scholarly texts as an object of study can probably be explained by the fact that it clearly belongs to the poetical literary genre and has a strong presence in poems and hymns that find their roots in Christian tradition; for instance, in the Carmina Burana [6] — see Carmina amatoria 'love songs' $\mathrm{N}^{\mathrm{o}} 114$ (2a) and $\mathrm{N}^{\mathrm{o}} 139(2 \mathrm{~b}):^{3}$
a. Prata iam rident omnia, est dulce flores carpere

\footnotetext{
${ }^{2}$ In the literal translation, the subscript "NOM" stands for the nominative case.

${ }^{3}$ Considered profane songs, the Carmina Burana were written by itinerant clerics (called golliards) and are in reality deeply rooted in Christian culture and rhetorics.
} 


\section{b. $\quad$ flore rident vario \\ prata iam serena;}

The English counterparts-with either meadows or pastures as grammatical subject of laugh - can also easily be found in the same literary genre; for instance in [39, p. 90], the XIX ${ }^{\text {th }}$ century English translation of a German hymn written in the XVII ${ }^{\text {th }}$ century by Henriette Maria Luise von Hayn:

Guided by his gentle staff

Where the sunny pastures laugh, ${ }^{4}$

I go in and out and feed,

Lacking nothing that I need;

When I thirst, my feet he brings

To the fresh and living springs.

or in a famous poem by William Blake called Laughing Song [4]:

(4) When the meadows laugh with lively green

And the grasshopper laughs in the merry scene.

When Mary and Susan and Emily

With their sweet round mouths sing $\mathrm{Ha}, \mathrm{Ha}, \mathrm{He}$.

We will show, in section 3.1.3, that Abélard's analysis of the metaphor involved in prata rident and presented in [33] is directly relevant to the question of lexical contextualism. But before we do so, let us offer our own linguistic analysis of what is at stake in the structural design of this expression.

\subsubsection{Preliminary linguistic analysis: two distinct collocational patterns}

It is essential to first distinguish two Latin constructions $\mathbf{C 1}$ and $\mathbf{C 2}$, together with their English equivalents: ${ }^{5}$

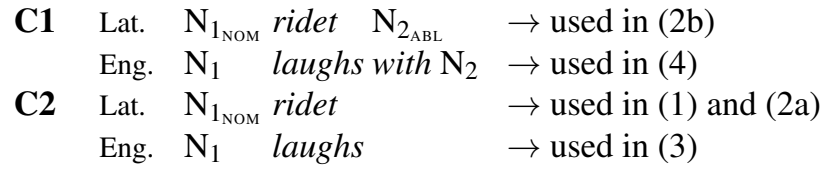

Though lexically and syntactically more complex, $\mathbf{C 1}$ has to be considered first because it somehow "explains" C2. In order to contrast the two constructions, we

\footnotetext{
${ }^{4}$ There is no German "pastures laugh" metaphor in the original hymn (entitled Weil ich Jesu Schäflein bin); the German corresponding verse only says Unaussprechlich süße Weide 'inexpressibly sweet meadow'.

${ }^{5}$ The subscript "ABL" stands for the ablative case. Because of the properties of Latin grammar,

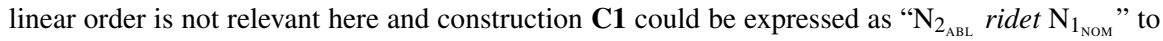
better reflect the linearization of lexical elements in $(2 b)$. The linearization used above was chosen because it shows better the parallel between the Latin and English versions of $\mathbf{C 1}$ and $\mathbf{C 2}$.
} 
will consider (5) below as a typical example for $\mathbf{C 1}$ and (1) above as a typical example for $\mathbf{C 2}$ :

$$
\begin{aligned}
& \text { Lat. Prata rident floribus. } \\
& \text { meadows } \mathrm{NOM}_{\mathrm{NO}} \text { laugh flowers } \\
& \text { 'The meadows bloom with flowers' }
\end{aligned}
$$

Both constructions $\mathbf{C} 1$ and $\mathbf{C} 2$ are collocations [12, 16], i.e. semi-idiomatic constructions that are made up of two distinct elements:

i) a base, that is chosen by the Speaker as a proper lexicalization for the meaning intended;

ii) a collocate, that is chosen by the Speaker "under the instruction of the base" in order to express a specific meaning next to the base.

One can see that this notion of collocation is mildly contextualist: it implies that the individual meaning (= the definition) of the collocate does not have to correspond exactly to the meaning it expresses once combined with the base. This contextualist flavor of the notion of collocation is however non-pragmatic in nature: a collocation is indeed to be conceived of as a lexical rule of the language, that is part of the lexical restricted combinatorics of the lexical unit functioning as base.

Using the notion of collocation, we can identify a major functional distinction between the two constructions we have identified.

FUNCTIONAL ANALYSIS OF C1 In (5), our prototypical example for construction $\mathbf{C 1}$, rident functions primarily as collocate of its complement floribus. It is used by the Speaker to express the fact that flowers are present in the meadows, and that this looks nice. In terms of Meaning-Text formal modelling of collocations, rident expresses here the standard lexical function BonInvolv [17, 26]. However, because the meaning 'meadows' and not 'flowers' is expressed in (5) in thematic position (as syntactic subject of the verb), a syntactic conversion applies in the collocation, which thus corresponds to a slightly more complex lexical function:

\section{Conv $_{21}$ Bonlnvolv.}

In other words, a dictionary for medieval Latin should specify in the entry for the noun FLŌS 'flower' that it can be used as oblique complement of the collocative verb RİDĔO, with any noun denoting a place as subject of this verb, in order to express the fact that the place in question is nicely covered with flowers. The same applies to dictionaries of contemporary English: if complete, they should indicate in their article for FLOWER that the verb BLOOM can take this noun as complement in order to express roughly the same collocational meaning:

$$
\text { The meadow/garden/balcony/... blooms with flowers. }
$$

Again, the very fact that any noun denoting a place can be the subject of blooms in (6), whereas only flowers (or names of flowers) can be used in the with-phrase complement, shows that it is the complement noun $\mathrm{N}_{2}$, and not the subject $\mathrm{N}_{1}$, that functionally controls construction $\mathbf{C 1}$-i.e., that is the base of the collocation.

FUnCTIONAL ANALYSis OF C2 Sentence (1) is as much a collocation as (5). However, as there is no $\mathrm{N}_{2}$ to talk about, it is obvious that the subject noun prata 
functions here as base. Now, it is not clear what exactly the collocate verb rident expresses in this collocation. Does (1) mean 'The meadows bloom'-the translation we offered earlier, when introducing the example — or simply something like 'The meadows are resplendent' (because their grass is very green, or because they are covered with flowers, etc.)? This question is legitimate and, unfortunately, only "native" speakers of medieval Latin could have answered it. In the absence of an informant, at least two facts can allow us to postulate a vaguer meaning for the collocate. First, this use of rident without complement is clearly derived from the full construction $\mathbf{C 1}$; in the process of losing a complement, the verb gains some lexical flesh but it does not necessarily incorporate 'flower' in its meaning. Going back in time, we know of at least one Roman text where the verb is used, in a collocation of the $\mathbf{C 1}$ type, with a vague meaning of 'be resplendent'—Horace, Ode XI, Book 4:

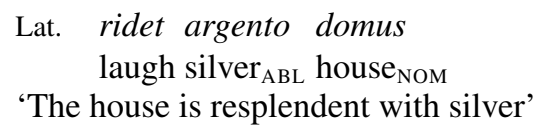

If in ancient Latin the verb RĪDĔO could be used as collocate of ARGENTUM in construction C1 to express 'be resplendent (with)', why could it not retain this vague meaning in medieval Latin when functioning as collocate of PRĀTUM in a C2 construction? Afterall, and this is our second argument, one finds in French a trace of this vague meaning in a collocative sense of the adjective RIANT lit. 'laughing':

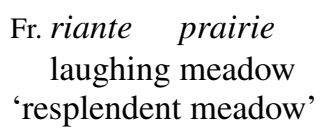

This collocation can well be used to refer to a meadow that is very green and radiant in the sun, but where flowers are not particularly noticeable. In conclusion, in (1), we simply cannot be sure of the exact meaning expressed by the verb, but we can be pretty sure the verb is indeed a collocate of its subject. Therefore, collocations of the $\mathbf{C} 2$ type are to be lexicographically accounted for in the dictionary entry for $\mathrm{N}_{1}$, where the verb RĪDĔO is mentioned as potential candidate for expressing the collocational meaning 'to look nice'. This is the same meaning expressed by the verb in construction C1, and it corresponds to the standard lexical function PredBon 'to be good'.

As we are clearly dealing with a specific, lexicalized sense of the vocable RĪDĔO, it is preferable to use a lexicographic numbering in order to clearly identify this lexical unit. We adopt the numbering of the Gaffiot Latin-French dictionary [10, p. 1364], where this unit is identified as RĪDĔO I.2[fig.]. Figure 1 below sumarizes the lexical function links that connect the three Latin lexical units PRĀTUM, FLŌS and RĪDĔO I.2[fig.], according to our linguistic analysis.

This figure shows that being able to use collocational constructions $\mathbf{C 1}$ and $\mathbf{C 2}$ is all about learning very specific lexical rules. These rules are making up part of our knowledge of a language and by no means should the use of that knowledge be forgotten when explaining how words make sense in given utterances. They make 
Fig. 1 Lexical function relations involved in collocations Prata rident floribus (construction $\mathbf{C 1} \rightarrow$ floribus is the base) $\sim$ Prata rident (construction $\mathbf{C 2} \rightarrow$ prata is the base)

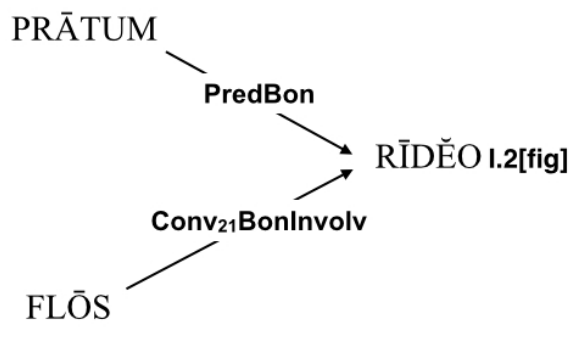

sense because the Speaker uses them to make sense, by diligently applying linguistic rules or, eventually, by creatively transgressing them.

It is not contexts that give meaning to words, it is the Speaker who uses linguistic rules to build sentences, and contexts are only symptoms: perceivable consequences of rule applications or transgressions.

Now that the system of lexical rules involved in $\mathbf{C 1}$ and $\mathbf{C 2}$ has been elicited, let us turn our attention to Pierre Abélard's analysis of Prata rident, as presented in [33].

\subsubsection{Abélard's monosemic credo}

Pierre Abélard—in his writings on logic—uses expressions such as Prata rident in order to elaborate on a strong postulate about words: each word has one and only one intrinsic meaning. This monosemic credo clearly follows from a biblical principle: each word has been institutionalized by Man, through the power granted to him by God, in order to name a given thing. ${ }^{6}$

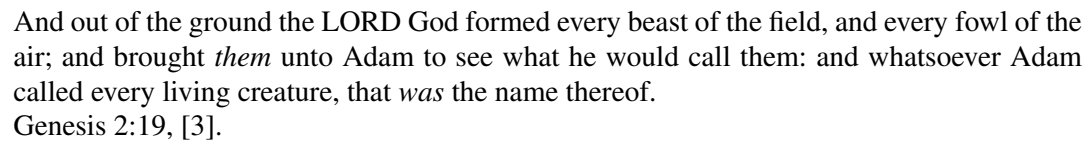

It follows from Abélard's perspective that, if a word does happen to be used in order to designate something of a different nature than what it has been institutionalized for, then:

1. this is a form of transgression-i.e., it is not something very good;

2. this can only happen by virtue of the context in which the word appears.

${ }^{6}$ The religious origin of Abélard's "monosemicism" is probably to be traced in other parts of the Bible as well. For instance, in the New Testament, more precisely the first verse of John's Gospel: "In the beginning was the Word, and the Word was with God, and the Word was God." If there can be only one God, and if the Word was God, it seems natural for a catholic to consider the word as deeply univocal. 
According to Abélard, if a word conveys in a sentence another content than its intrinsic meaning (because of a Speaker's rhetorical figure, error, etc.), this "improper" content is given to the word by the context in which it appears. Thus, in (1), the context "Prata__ " gives to rident the meaning 'to flower', that cannot belong to the verb RĪDĔO on the premise that it has one and only one meaning 'to laugh' [33, p. 158].

Abélard fails to notice that a much vaguer meaning than 'to flower' could be associated to the verb-as we did in our analysis, section 3.1.2—, in order to account for other similar usages. He also does not identify the fundamental functional differences between constructions $\mathbf{C 1}$ and $\mathbf{C 2}$, focussed as he is on the "deviant" use of the verb. His credo about the fundamental semantic univocity of words forbids him completely from seeing that some subtle lexical rules are activated when ridere is used as collocate (figure 1) and that context has very little to do in terms of explaining where meaning comes from.

Abélard's attitude towards word meaning is a prototypical illustration of philosophical, non-linguistic approaches to the study of language. Instead of being driven by systematic logical observation of linguistic facts, it is designed to abide by general axioms about God, Man and the relation between them.

\subsection{The upside-down approach to linguistic meaning}

Clearly, Abélard is a die-hard lexical contextualist. But his monosemic credo is somehow logical and fully justified from a philosophical point of view. It is less understandable though that the same credo about the unicity of meaning finds its way into contemporary linguistics. For instance, while the Generative Lexicon put forward by James Pustejovsky [29] aims primarily at dealing with polysemy, it presupposes that each polysemic word happens to possess one core, orignal meaning, from which all other senses can be derived through inference rules by virtue of the word being used in given contexts; cf. [30, p. 293]:

Whereas sense enumeration approaches to meaning construct a Linnaeus-like museum of word senses, with genus and species neatly classified and separated into distinct cases, in Generative Lexicon Theory the methodology has been to construct differential structures that have functional behaviors. More specifically, (a) the semantics of lexical items are underspecified expressions, (b) every element in a phrase may function "actively" in the composition of the phrase, and (c) the notion of word sense only emerges at the level of the sentence, namely, its "sense in context."

The motivation behind Abélard's postulate is clear, but what motivates this urge for unicity among modern scholars, whose frame of analysis is supposed to be unrelated to any theological doctrine?

One has to grant the Generative Lexicon a practical motivation: natural language processing — in particular, automatic text analysis - has to cope with any sense a word could carry while, at the same time, no lexical ressource will ever be rich and detailed enough to provide computer programs with a complete enumeration of 
these senses and solve the ambiguity problem. And here, we put our finger on another fact that should help us understand the omnipresence of lexical contextualism:

When studying language, people have the unconscious reflex of putting themselves in the Addressee's shoes instead of systematically adopting the Speaker perspective.

Take a sentence, any sentence; Prata rident, for instance. The very presence before us of Prata rident presupposes at least three essential participating elements, besides the sentence itself:

1. the Language-Prata rident is a Latin sentence, not an English or Russian one, and this means that it follows the rules of a complex system, that we call Latin;

2. the Speaker-if Prata rident exists in speech, someone has uttered or written it;

3. the Addressee-if Prata rident is bound to function in semiosis, it means that there is or will be at least one person performing the act of comprehending it (and the Speaker knows this).

Linguists or philosophers who are reflecting on this sentence can identify themselves to two of these participating elements: the Speaker or the Addressee. This leaves us with three logically possible methodologies for examining language: one can take the Speaker perspective, the Addressee perspective or a combo SpeakerAddressee perspective.

The last perspective, the combo one, can hardly be adopted as it is virtually impossible to focus on the description of a sentence by taking simultaneously the place of the Speaker and the Addressee. As stated above, it is the Addressee perspective that is almost always adopted in language studies. Because most people are unaware of this, it is worth listing a few facts that directly reflect the omnipresence of the Addressee perspective in language studies:

- the fact that Linguistics 101 courses or, more generally, introductions to the study of language, are generally structured from phonetics to semantics, through morphology and syntax, instead of proceeding exactly the other way round (from meanings to be expressed to modes of expression of these meanings);

- the fact of focussing on ambiguity - a problem the Addressee has to solveinstead of focussing on synonymy/paraphrase - a set of choices made available to the Speaker by natural languages;

- the fact that the terms analysis, interpretation, parsing are omnipresent in linguistic texts, whereas synthesis, production, generation are much rarer;

- the fact that the semantic module of languages is often presented as being an interpretation module, for instance in so-called formal semantics [21, 22];

- the fact of referring to a syntax-semantics interface instead of a semantics-syntax interface. ${ }^{7}$

\footnotetext{
${ }^{7}$ At the time of writing, the syntax-semantics+interface query returned 81,000 hits on Google, against a meager 2,840 hits for semantics-syntax+interface.
} 
We could continue this enumeration almost endlessly. As a rule, language studies are wall-to-wall Addressee-oriented. Let us mention two black sheeps, two theoretical approaches in modern linguistics that are designed specifically in order to model languages from content to form, and not the other way round:

- Michael Halliday's Systemic Functional Linguistics [11];

- Igor Mel'čuk's Meaning-Text linguistics $[15,18,20]$.

In Meaning-Text linguistics, in particular, the Meaning-to-Text orientation is explicitly presented as a methodological prerequisite for effective linguistic study. As stated by Mel'čuk [19, p. 122]:

From the viewpoint of linguistic communication, the two directions are equally important as well: both the Speaker and the Addressee are vital for an act of communication.

As a consequence, one might think that choosing the orientation of linguistic description in an MTM [= Meaning-Text Model] is of not too great an importance. Thus, in the majority of linguistic theories I know of the description of a language is carried out in the direction "Texts $\Rightarrow$ Meanings," i.e., in the direction of analysis. However, I think that the orientation of linguistic description is of utmost importance, and the opposite direction-"Meanings $\Rightarrow$ Texts," i.e., synthesis — seems by far more useful and promising.

It is this Speaker-oriented approach that we have adopted in our analysis of Prata rident and other related sentences (3.1.2), because only this can make us "see" fully the linguistic rules that allow for these sentences to be assembled and, therefore, to exist. However, in our experience, the systematic examination of linguistic objects from the Speaker viewpoint is one of the main reasons why it seems so difficult for many to follow Meaning-Text arguments and demonstrations.

While the Speaker perspective is explicitly stated in Meaning-Text linguistics as a necessary condition for good linguistic study, the Addressee perspective is generally chosen by default, in an unconscious way, by people who are more often than not simply unaware (a) that two alternative approaches logically exist and (b) that they are de facto adopting one of them.

Reasons for considering that the Speaker perspective is the right one in linguistics need to be discussed at length, and a detailed argumentation can be found in [19, p. 122-148]. We will limit ourselves to two observations, that may not be definite arguments but that are based, at least, on rather objective facts about language and linguistic processes.

Firstly, there is inherent sequentiality in the communication process:

1. the Speaker makes up and expresses a linguistic content;

2. then the utterance exists as a fact;

3. finally the Addressee interprets this utterance.

Though the interpretation process may occur almost simultaneously, a chunk of utterance is interpreted inasmuch as it has been uttered in spoken language. In written language, the sequentiality is more obvious, even though the Addressee may anticipate what he/she is about to read: the actual interpretation takes place (as confirmation of anticipation) only when actual reading is performed. Therefore, the synthesis process is primary in time. 
Secondly, language is knowledge, i.e. information in mind. This knowledge is knowledge of signs and sign combination rules that are used both by the Speaker in the production process and by the Addressee in the interpretation process. But the difference between active and passive mastering of language shows, at the level of performance, that the interpretation process relies heavily on extra-linguistic knowledge as well, to the extent that we may be able to interpret sentences in a language that we do not master, whereas we could never assemble sentences in order to express given contents without a good mastering of the language. Therefore, adopting the Speaker perspective helps us to focus on linguistic knowledge because speaking is a much more language-based activity than interpreting.

Of course, everyone is entitled to reject these arguments; but at least researchers should, first, acknowledge the fact that they do make a choice by adopting an opposite Addressee perspective and, second, explain why their approach is better.

Adopting the Speaker perspective truly makes things easier for linguists, language teachers, etc. In contrast, we are convinced that the analytical approach has catastrophic effects: it is an upside-down approach, leading to inside-out models, to spending much time and energy on trying to solve problems that either are not the right ones or do not exist in language use. Methodology should be as central in linguistics as it is in any other science, and the fact of adopting the Speaker perspective does make a difference in language studies. As stated very clearly by Mel'čuk [19, p. 147]:

The intuition of a linguist, which is so important in linguistic research, functions much better in the direction of synthesis. It seems easier for introspection to figure out the ways in which a given meaning can be expressed than to deal with formally possible (even if absurd) interpretations of a given text.

In a nutshell, the right question to ask ourselves when faced with a linguistic expression should be:

\section{"How did the Speaker do it?"}

So why is the Addressee perspective so systematically adopted? On the one hand, it can be the result of an academic conditioning. ${ }^{8}$ Most linguists, students, language teachers are just acting the way they have been trained to act, because of a conditioning that results from reading over and over again statements such as the following upside-down definition of language offered by the philosopher David Lewis [14, p. 3]:

What is a language? Something which assigns meanings to certain strings of types of sounds or of marks. It could therefore be a function, a set of ordered pairs of strings and meanings.

\footnotetext{
${ }^{8}$ This is at least our own personal experience. As a Ph.D. student, we had to go through a rather long process of deconditioning, which made us aware of the fact that the upside-down view of language was instilled in us by the sheer fact that it is overwhelmingly present in language studies. Yes, our deconditioning took place via a reverse process of reconditioning. At least, we went through it consciously, and it felt good because it simply helped "doing things" with language and linguistics.
} 
Another possible explanation is that this Addressee-identification reflex finds some of its roots deep in cultural conditioning and in the structures of language itself. For instance, one can easily find in English, French, etc., words that relate to the fact of speaking too much (to babble, to blather, to gossip, babbler, chatter, chatterbox, gabbler, magpie, pratter, garrulous, gassy, gossipy, long-winded, verbose, wordy ...), but it is much harder to find in our lexicons words denoting excessive listening. Language itself imposes on us a vision of linguistic interaction where speaking has more chance to be the wrong thing to do than listening. God speaks and Man listens, as it goes. Whether we are believers or atheists, we cannot escape the fact that in occidental cultures our right place seems to be the place of the listener. ${ }^{9}$ This explanation may seem far-fetched, and maybe it is, but we find it quite appealing as a working hypothesis for someone who may want to study the question of general linguistic methodologies from an epistemological viewpoint. Indeed, it nicely connects our two explanations for the omnipresence of lexical contextualism: the word monosemy dogma (section 3.1) and the upside-down Addressee perspective.

For this reason, let us call this lexical contextualism of mixed origins, that manifests itself in linguistics and in the philosophy of language, the Abélard syndrome.

\subsection{Connecting the dots}

Not only the Abélard syndrome acts as blinders in languages studies, but it seems to breed pure and simple sense denial, especially when scholars start to voice out murderous ideas about polysemy; cf. Geoffrey Nunberg concluding his analysis of the notion of word meaning as regards to polysemy [25, p. 177]:

In the end, my point is simply this. Linguists have postulated that words have 'meanings-inthe-language' because it seemed necessary to do so, in order to explain how novel utterances are understood. It turns out, however, that this hypothesis is too strong, and that it would force us to make assumptions about our language over and above what simple understanding would require. We do not have to know what a word names to be able to say what it is being used to refer to.

And a few lines below:

All that linguistic semantics should be asked to provide is an account of how languages come to be used and understood, and we can do that, it turns out, without having to say that speakers know what words mean.

These ideas are also promoted by trigger-happy philosophers when they turn upon polysemy, word meaning and any attempt at offering descriptive models of word senses; cf. Jerry Fodor on Ray Jackendoff's semantic theory [8, p. 50]:

\footnotetext{
${ }^{9}$ We do not intend to imply that this is a distinctive characteristic of occidental cultures. Confucianism, for instance, clearly puts very strong emphasis on listening as a virtue: "Listen widely to remove your doubts and be careful when speaking about the rest and your mistakes will be few" $[1,2: 18]$. What we mean is that such is not necessarily the case in all cultures and that adopting the Speaker perspective may indeed seem like a more natural thing to do in some.
} 
I claim that Jackendoff's account of polysemy offers no good reason to think that there are definitions. As often happens in lexical semantics, the problem that postulating definitions is supposed to solve is really only begged; it's, as it were, kicked upstairs into the metalanguage.

And because Fodor loves his own metaphors, he does not hesitate to do some recycling when attacking this time, with Ernest Lepore, the Generative Lexicon approach to polysemy $\left[9\right.$, p. 279-280]: ${ }^{10}$

This is just the polysemy problem all over again; all that's happened is that it has been kicked upstairs from the semantics to the ontology: whereas we used to worry about how to count senses, we are now invited to worry about how to count processes. Six of one, half a dozen of the other.

Ideologues of linguistics and the philosophy of language such as Nunberg or Fodor are successful because they sow on fertile soil: the Abélard syndrome prevails and sense denial rhetoric probably echoes a need for comfort experienced by people who find themselves unable to apprehend language as a true object of study. It seems easier to say that there is no meaning and therefore to dispense with the burden of performing actual descriptive work.

\section{In form of conclusion}

It is time to conclude this reflection on lexical contextualism with an important remark: at no time do we pretend that linguistic context has no role to play in shaping the semiotic content carried by linguistic expressions as speech tokens. For instance, we have no problem with John Firth's famous aphorism [7, p. 190]:

[The use of the word 'meaning' is subject to the general rule that] each word when used in a new context is a new word.

But this sentence has to be put in its context, whereas meaning negationists citing Firth almost systematically fail to recall (maybe because they have not read the text from which the quote comes) that Firth's concern in his essay Modes of Meanings is primarily about tokens and not types, about parole in the Saussurian sense and not langue. Essentially, people forget that this paper deals with what Firth calls phonological modes of meaning and collocational modes of meaning in literary texts, mainly poetry, and epistolary literature. It is focussing on creativity and individual realization. To quote another of Firth's aphorisms, p. 193:

[To begin with, we must apprehend language events in their contexts as shaped by the creative acts of speaking persons.] Whenever a man speaks, he speaks in some sense as a poet.

Even if we disregard the creative aspect of language use, we have no doubt that words do not make sense in isolation. Within language as knowledge-in the mental

\footnotetext{
${ }^{10}$ See [30] for a detailed answer by James Pustejovsky to Fodor and Lepore criticisms.
} 
lexicon $[2,38,40]$ - words are not isolated: their inherent semiotic value is a factor of their position in the global lexical system $[27,28] .{ }^{11}$ Experienced lexicographers, translators or language teachers never consider a word in isolation. They will never consider, for instance, just the form wave; they will mentally picture wave in various contexts that act as signatures for corresponding senses:
a. sea, high, strong wave
b. wave of protests, strikes
c. Wave your hand
etc.

As speakers who construct and utter sentences, they will focus on actual lexical signs, not forms. In their mind, they will necessarily associate each word with a network of paradigmatic and syntagmatic connections that conditions a specific sense.

Thinking about it: if it were to be understood in reference to lexical networks as contexts, lexical contextualism could even be said to be the right approach to lexical semantics.

Acknowledgements Many thanks to Helen Lim for her feedback on the draft version of this paper, and for accepting to indulge in philosophical chats with us.

\section{References}

1. Analects of Confucius. Available at http://www.acmuller.net/con-dao/ analects.html.

2. Aitchison, Jean. 2012. Words in the Mind: An Introduction to the Mental Lexicon. $4^{\text {th }}$ edition, Oxford: Wiley-Blackwell.

3. King James Bible "Authorized Version". Cambridge Edition. Available at http://www . kingjamesbibleonline.org/.

4. Blake, William. 1789. Songs of Innocence. Available at http://www .blakearchive. org/exist/blake/archive/work.xq?workid=s-inn\&java=no.

5. Cappelen, Herman, and Ernest Lepore. 2005. Insensitive Semantics: A Defense of Semantic Minimalism and Speech Act Pluralism. Oxford: Wiley-Blackwell.

6. Carmina Burana. ca. 1230. Codex latinus Monacensis. Codex clm 4660 and 4660a. Munich: Bavarian State Library.

7. Firth, John Rupert. 1957 [1951]. Modes of Meaning. In Papers in Linguistics 1934-1951, 190-215. London: Oxford University Press [First published in Essays and Studies (The English Association), 1951].

8. Fodor, Jerry A. 1998. Concepts. Where Cognitive Science Went Wrong. Oxford Cognitive Science Series, Oxford: Oxford University Press.

9. Fodor, Jerry A., and Ernest Lepore. 1998. The Emptiness of the Lexicon: Reflections on James Pustejovsky's The Generative Lexicon. Linguistic Inquiry 29(2):269-288.

10. Gaffiot, Félix. 1934. Dictionnaire latin-français. Paris: Hachette.

${ }^{11}$ For instance, figure 1, section 3.1.2, is a hypothesized micro-sample of the global lexical system of Latin. 
11. Halliday, Michael A. K., and Christian M. I. M. Matthiessen. 2004. An introduction to functional grammar. $3^{\text {rd }}$ edition, London: Hodder Arnold [First edition by Michael Halliday in 1985].

12. Hausmann, Franz Josef. 1979. Un dictionnaire des collocations est-il possible? Travaux de littérature et de linguistique de l'Unviersité de Strasbourg XVII(1):187-195.

13. Kilgarriff, Adam. 1997. I don't believe in word senses. Computers and the Humanities 31:91113.

14. Lewis, David. 1975. Languages and Language. In Language, Mind and Knowledge, ed. Keith Gunderson, 3-35. Minneapolis: University of Minnesota Press.

15. Mel'čuk, Igor. 1973. Towards a Linguistic "Meaning $\Leftrightarrow$ Text" Model. In Trends in Soviet Theoretical Linguistics, ed. Ferenc Kiefer, 33-57. Dordrecht: Reidel.

16. Mel'čuk, Igor. 1995. Phrasemes in Language and Phraseology in Linguistics. In Idioms: Structural and Psychological Perspectives, eds. Martin Everaert, Erik-Jan van der Linden, André Schenk and Rob Schreuder, 167-232. Hillsdale, N.J.-Hove, UK: Laurence Erlbaum Associates.

17. Mel'čuk, Igor. 1996. Lexical Functions: A Tool for the Description of Lexical Relations in the Lexicon. In Lexical Functions in Lexicography and Natural Language Processing, ed. Leo Wanner, 37-102. Language Companion Series 31, Amsterdam/Philadelphia: John Benjamins.

18. Mel'čuk, Igor. 1997. Vers une linguistique Sens-Texte. Leçon inaugurale. Paris: Collège de France.

19. Mel'čuk, Igor. 2012. Semantics: From meaning to text. Studies in Language Companion Series 129, Amsterdam/Philadelphia: John Benjamins.

20. Milićević, Jasmina. 2006. A Short Guide to the Meaning-Text Linguistic Theory. Journal of Koralex 9:187-233.

21. Montague, Richard. 1970. Universal grammar. Theoria 36(3):373-398.

22. Montague, Richard. 1973. The Proper Treatment of Quantification in Ordinary English. In Approaches to Natural Language, eds. Jaako Hintikka, Julius Moravcsik and Patrick Suppes, 221-242. Dordrecht: Reidel.

23. Montminy, Martin. 2010. Two contextualist fallacies. Synthese 173(3):317-333.

24. Norén, Kerstin, and Per Linell. 2007. Meaning Potentials and the Interaction between Lexis and Contexts: An Empirical Substantiation. Pragmatics 17(3):387-416.

25. Nunberg, Geoffrey. 1979. The Non-Uniqueness of Semantic Solutions: Polysemy. Linguistics and Philosophy 3(2):143-184.

26. Polguère, Alain. 2007. Lexical function standardness. In Selected Lexical and Grammatical Issues in the Meaning-Text Theory. In Honour of Igor Mel'čuk, ed. Leo Wanner, 43-95. Language Companion Series 84, Amsterdam/Philadelphia: Benjamins.

27. Polguère, Alain. 2009. Lexical systems: graph models of natural language lexicons. Language Resources and Evaluation 43(1):41-55.

28. Polguère, Alain. To appear. Principes de modélisation systémique des réseaux lexicaux. Actes de la $21_{e}$ Conférence sur le Traitement Automatique du Langage Naturel (TALN 2014), Marseille.

29. Pustejovsky, James. 1995. The Generative Lexicon. Cambridge, Massachusetts \& London, England: MIT Press.

30. Pustejovsky, James. 1998. Generativity and Explanation in Semantics: A Reply to Fodor and Lepore. Linguistic Inquiry 29(2):289-311.

31. Queiroz, João, and Floyd Merrell. 2006. Semiosis and pragmatism: Toward a dynamic concept of meaning. Sign Systems Studies 34(1):37-65.

32. Recanati, Franois. 2004. Literal Meaning. Cambridge: Cambridge University Press.

33. Rosier-Catach, Irène. 1997. Prata rident. In Langages et philosophie : hommage à Jean Jolivet, eds. Alain de Libera, Abdelali Elamrani-Jamal and Alain Galonnier, 155-176. Études de philosophie médiévale 74, Paris: J. Vrin.

34. Saussure, Ferdinand de. 1916. Cours de linguistique générale. Edited by Charles Bally and Albert Sechehaye, with the collaboration of Albert Riedlinger. Lausanne-Paris: Payot.

35. Searle, John. 1980. The background of meaning. In Speech act theory and pragmatics, eds. Searle, John, Ferenc Kiefer, and Manfred Bierwisch, 221-232. Dordrecht: Reidel. 
36. Stanley, Jason. 2004. On the Linguist Basis for Contextualism. Philosophical Studies 119:119-146.

37. Wierzbicka, Anna. 1992. Back to definitions: Cognition, semantics, and lexicography. Lexicographica 8:146-174.

38. Wierzbicka, Anna. 2009. The Theory of the Mental Lexicon. In Die slavischen Sprachen/The Slavic Languages: An International Handbook of their Structure, their History and their Investigation, eds. Kempgen, Sebastian, Peter Kosta, Tilman Berger, and Karl Gutschmidt, 848863. Berlin \& New York: Mouton de Gruyter.

39. Winkworth, Catherine. 1863. Lyra Germanica: Second Series: The Christian Life. London: Longman, Green, Longman, and Roberts.

40. Zock, Michael, and Didier Schwab. 2011. Storage does not Guarantee Access: The Problem of Organizing and Accessing Words in a Speaker's Lexicon. Journal of Cognitive Science $12: 233-259$ 